\title{
Acoustic-Frequency Vibratory Stimulation Regulates the Balance between Osteogenesis and Adipogenesis of Human Bone Marrow-Derived Mesenchymal Stem Cells
}

\author{
Xi Chen, ${ }^{1,2}$ Fan He, ${ }^{1}$ Dong-Yan Zhong, ${ }^{1}$ and Zong-Ping Luo ${ }^{1}$ \\ ${ }^{1}$ Orthopaedic Institute, Soochow University, Department of Orthopaedics, the 1st Affiliated Hospital of Soochow University, \\ Suzhou, Jiangsu 215007, China \\ ${ }^{2}$ School of Biology and Basic Medical Sciences, Medical College, Soochow University, Suzhou, Jiangsu 215123, China \\ Correspondence should be addressed to Zong-Ping Luo; zongpingluo@yahoo.com
}

Received 11 December 2014; Accepted 19 January 2015

Academic Editor: Elena Jones

Copyright (C) 2015 Xi Chen et al. This is an open access article distributed under the Creative Commons Attribution License, which permits unrestricted use, distribution, and reproduction in any medium, provided the original work is properly cited.

\begin{abstract}
Osteoporosis can be associated with the disordered balance between osteogenesis and adipogenesis of bone marrow-derived mesenchymal stem cells (BM-MSCs). Although low-frequency mechanical vibration has been demonstrated to promote osteogenesis, little is known about the influence of acoustic-frequency vibratory stimulation (AFVS). BM-MSCs were subjected to AFVS at frequencies of $0,30,400$, and $800 \mathrm{~Hz}$ and induced toward osteogenic or adipogenic-specific lineage. Extracellular matrix mineralization was determined by Alizarin Red S staining and lipid accumulation was assessed by Oil Red O staining. Transcript levels of osteogenic and adipogenic marker genes were evaluated by real-time reverse transcription-polymerase chain reaction. Cell proliferation of BM-MSCs was promoted following exposure to AFVS at $800 \mathrm{~Hz}$. Vibration at $800 \mathrm{~Hz}$ induced the highest level of calcium deposition and significantly increased mRNA expression of COL1A1, ALP, RUNX2, and SPP1. The $800 \mathrm{~Hz}$ group downregulated lipid accumulation and levels of adipogenic genes, including FABP4, CEBPA, PPARG, and LEP, while vibration at $30 \mathrm{~Hz}$ supported adipogenesis. BM-MSCs showed a frequency-dependent response to acoustic vibration. AFVS at $800 \mathrm{~Hz}$ was the most favorable for osteogenic differentiation and simultaneously suppressed adipogenesis. Thus, acoustic vibration could potentially become a novel means to prevent and treat osteoporosis.
\end{abstract}

\section{Introduction}

Osteoporosis is a systemic disease characterized by low bone mass and deterioration of the bone microarchitecture, resulting in increased bone fragility and susceptibility to fracture. Worldwide, 9 million people suffer from osteoporosis-related fractures every year [1] and more importantly, osteoporosisrelated fractures are a major cause of morbidity and mortality. For example, in the United States, more than 30,000 deaths within half a year are imputed to hip fractures [2]. Current osteoporosis treatments predominantly use boneantiresorptive drugs that are associated with several side effects without fully restoring the balance between bone resorption and formation $[3,4]$.

The disorders of bone remodeling are accompanied by an increase in marrow fat and a decline in bone mass [5].
The balance between osteogenesis and adipogenesis of bone marrow-derived mesenchymal stem cells (BM-MSCs), as the common progenitors of osteoblasts and adipocytes [6], plays an important role in maintaining bone homeostasis. Therefore, the shift of BM-MSC differentiation into the adipocyte lineage may result in inadequate bone formation and excessive fat production [7]. The differentiation of BMMSCs is regulated by transcription factors, which affect the lineage fate determination. More specifically, peroxisome proliferator-activated receptor- $\gamma$ (PPAR- $\gamma$ ) promotes adipogenesis while inhibiting osteogenesis, whereas runt-related transcription factor 2 (Runx2) enhances osteogenesis instead of adipogenesis. PPAR- $\gamma$ can suppress the activity of Runx2 and thus inhibits expression of osteogenesis-related genes [8].

The growing number of evidence has demonstrated the role of both biochemical and biomechanical signals 
in regulating MSC lineage-specific differentiation, where mechanical stimuli affect the metabolism of bone cells and their precursors. Low-frequency vibration can enhance bone remodeling, prevent bone loss, and improve bone healing in both animals and humans [9]. Furthermore, mechanical stimulation can direct the lineage commitment of MSCs by biasing cell fate in favor of osteogenesis, suggesting that MSCs may sense the vibratory frequencies [10-12]. Luu et al. reported that a daily exposure to low magnitude mechanical signals facilitated MSC proliferation and osteogenic differentiation [13]. Presently, little is known about the simultaneous regulation of mechanical vibration, especially at acoustic frequencies, on osteogenesis and adipogenesis of BM-MSCs, which significantly limits our understanding of the role of the mechanical stimuli on this critical osteoporotic mechanism.

In this study, we investigated the role of acousticfrequency vibratory stimulation (AFVS) at 30, 400, and $800 \mathrm{~Hz}$, which generated the same vibration amplitude of the cell culture plates, in regulating proliferation, osteogenesis, and adipogenesis of BM-MSCs. Expression of adipogenic and osteogenic marker genes, their functional capacity to form mineralized extracellular matrix (ECM), and lipid accumulation in the differentiated cells were examined. We hypothesized that the responses of BM-MSCs to acoustic vibration could highly depend on the frequency and that the higher frequency vibration could determine the lineage fate of MSCs.

\section{Materials and Methods}

2.1. Cell Culture of BM-MSCs. Human BM-MSCs (American Type Culture Collection, Manassas, VA, USA) were cultured in $175 \mathrm{~cm}^{2}$ cell culture flasks (Corning, Tewksbury, MA, USA) in modified Eagle's medium alpha supplemented with $10 \%$ fetal bovine serum (FBS), $100 \mathrm{U} / \mathrm{mL}$ penicillin, and $100 \mu \mathrm{g} / \mathrm{mL}$ streptomycin (GIBCO, Carlsbad, CA, USA) at $37^{\circ} \mathrm{C}$ in a humidified $5 \% \mathrm{CO}_{2}$ atmosphere. Upon reaching $70 \%$ confluence, cells were dissociated by $0.25 \%$ trypsinEDTA (Invitrogen Carlsbad, CA, USA) and reseeded into 96well and 12-well plates for the next stage of the experiments.

2.2. Acoustic Frequency Loading Platform. A vibration loading of cell cultures was developed to stimulate BM-MSCs with different vibrations. 12-well plates cultured with BMMSCs were mounted onto the platform of a vibration shaker (U8556001, 3B Scientific, Hamburg, Germany), which was excited by one channel of functional generator (ATF20B, ATTEN, Shenzheng, China) providing the amplitude, waveform, and frequency of the vibration. When the platform was placed in the cell culture incubator, BM-MSCs cultures received vertical sinusoid stimuli (magnitude of $0.3 \mathrm{~g}$, frequencies of $0,30,400$, and $800 \mathrm{~Hz}$ ) for $30 \mathrm{~min}$ per day [14, 15].

2.3. Cell Viability Stain and Cell Proliferation Assay. 1000 cells/well of BM-MSCs were seeded in a 96-well flatbottomed plate at $37^{\circ} \mathrm{C}$ in $5 \% \mathrm{CO}_{2}$. The cells were treated with acoustic vibratory stimulation for $30 \mathrm{~min}$ each day at the frequency of $0,30,400$, or $800 \mathrm{~Hz}$, in hexaplicate wells. After 7 days, cell viability was assessed by fluorescein diacetate
(FDA; Sigma-Aldrich, St Louis, MO, USA) staining [16]. Cells were incubated in $5 \mu \mathrm{g} / \mathrm{mL}$ FDA solution at $37^{\circ} \mathrm{C}$ for $10 \mathrm{~min}$ and fluorescence images were captured with an Olympus IX51 microscope (Olympus Corporation, Tokyo, Japan). Cell proliferation was evaluated using the Cell Counting Kit8 (CCK-8; Beyotime Institute of Biotechnology, Haimen, China). Briefly, $10 \mu \mathrm{L}$ of the CCK- 8 solution was added to each well and the cells were incubated at $37^{\circ} \mathrm{C}$ for $1 \mathrm{~h}$. Absorbance was determined at $450 \mathrm{~nm}$ using a microplate spectrophotometer (BioTek, Winooski, VT, USA).

2.4. Osteogenic Differentiation of BM-MSCs and Alizarin Red $S$ Staining. To induce BM-MSCs into osteoblasts, cells were cultured in osteogenic differentiation medium (DMEM (low glucose) supplemented with $10 \%$ FBS, $100 \mathrm{U} / \mathrm{mL}$ penicillin, $100 \mu \mathrm{g} / \mathrm{mL}$ streptomycin, $2 \times 10^{-4} \mathrm{M} \mathrm{L}$-ascorbic acid, $10^{-7} \mathrm{M}$ dexamethasone, and $10^{-2} \mathrm{M} \beta$-glycerophosphate disodium salt hydrate (Sigma-Aldrich)) for 14 days $[17,18]$. The differentiation medium was changed every 3 days.

Calcium deposition in the extracellular matrix was determined by Alizarin Red S staining after 7 and 14 days of osteogenic differentiation. Cells were fixed in $4 \%$ polyoxymethylene (Sigma-Aldrich) and then incubated in $1 \%$ Alizarin Red S solution ( $\mathrm{pH}=4.3$; Sigma-Aldrich). Images of calcium deposition were captured with an Olympus IX51 microscope. To quantify the calcium deposition, $200 \mu \mathrm{L} /$ well of $1 \%$ hydrochloric acid (Sigma-Aldrich) was added and absorbance was measured at $420 \mathrm{~nm}$ using a microplate spectrophotometer (BioTek).

2.5. Adipogenic Differentiation of BM-MSCs and Oil Red O Staining. To induce BM-MSCs into adipocytes, cells were cultured in adipogenic differentiation medium (DMEM [high glucose] supplemented with $10 \%$ FBS, $100 \mathrm{U} / \mathrm{mL}$ penicillin, $100 \mu \mathrm{g} / \mathrm{mL}$ streptomycin, $10^{-6} \mathrm{M}$ dexamethasone, $5 \times 10^{-4} \mathrm{M}$ 3-isobutyl-1-methylxanthine, $10 \mathrm{mg} / \mathrm{L}$ insulin, and $10^{-4} \mathrm{M}$ indomethacin (Sigma-Aldrich)) for 21 days [17]. The differentiation medium was changed every 3 days.

The differentiated BM-MSCs were stained with Oil Red $\mathrm{O}$ after 14 and 21 days of adipogenic differentiation. The induced adipocytes were fixed with $10 \%$ buffered formaldehyde (Sigma-Aldrich) and then incubated in Oil Red O solution (Sigma-Aldrich) for $30 \mathrm{~min}$ at room temperature. Images of adipocytes were captured with an Olympus IX51 microscope. To quantify the induced adipocytes, $200 \mu \mathrm{L} /$ well of isopropanol was added and absorbance was measured at $510 \mathrm{~nm}$ using a microplate spectrophotometer (BioTek).

2.6. Total RNA Extraction and Real-Time Reverse Transcription-Polymerase Chain Reaction (Real-Time RT-PCR). Total RNA was extracted (from four groups of cells per experimental condition) using TRIzol reagent (Sigma-Aldrich) and $1 \mu \mathrm{g}$ of total RNA was reverse-transcribed using the RevertAid First Strand cDNA Synthesis Kit (Thermo Fisher Scientific). To quantify mRNA expression, an amount of cDNA equivalent to $20 \mathrm{ng}$ of total RNA was amplified by real-time PCR using the iTap Universal SYBR Green Supermix kit (Bio-Rad, Hercules, CA, USA). Transcript levels of osteogenic marker genes (ALP, COL1A1, SPP1/OPN, and RUNX2), adipogenic 
TABLE 1: Primers used for real-time RT-PCR.

\begin{tabular}{|c|c|c|}
\hline Gene & Primer sequence $\left(5^{\prime}-3^{\prime}\right)$ & GeneBank accession \\
\hline \multicolumn{3}{|c|}{ The internal standard gene } \\
\hline GAPDH & F: AGAAAAACCTGCCAAATATGATGAC & \multirow{2}{*}{ NM_002046 } \\
\hline जАРDП & R: TGGGTGTCGCTGTTGAAGTC & \\
\hline \multicolumn{3}{|c|}{ Osteogenic marker genes } \\
\hline \multirow{2}{*}{ COL1A1 } & F: CAGCCGCTTCACCTACAGC & \multirow{2}{*}{ NM_000088.3 } \\
\hline & R: TTTTGTATTCAATCACTGTCTTGCC & \\
\hline \multirow{2}{*}{$A L P$} & F: AGCACTCCCACTTCATCTGGAA & \multirow{2}{*}{ NM_000478.3 } \\
\hline & R: GAGACCCAATAGGTAGTCCACATTG & \\
\hline \multirow{2}{*}{$S P P 1 / O P N$} & F: GCGAGGAGTTGAATGGTG & \multirow{2}{*}{ NM_013227.2 } \\
\hline & R: CTTGTGGCTGTGGGTTTC & \\
\hline \multirow{2}{*}{ RUNX2 } & F: AGAAGGCACAGACAGAAGCTTGA & \multirow{2}{*}{ NM_001015051.3 } \\
\hline & R: AGGAATGCGCCCTAAATCACT & \\
\hline \multirow{3}{*}{$F A B P 4$} & Adipogenic marker genes & \multirow{3}{*}{ NM_001442.2 } \\
\hline & F: AACCTTAGATGGGGGTGTCCTG & \\
\hline & R: TCGTGGAAGTGACGCCTTTC & \\
\hline \multirow{2}{*}{ CEBPA } & F: CGGTGGACAAGAACAGCAAC & \multirow{2}{*}{ NM_004364 } \\
\hline & R: CGGAATCTCCTAGTCCTGGC & \\
\hline \multirow{2}{*}{ LEP/Leptin } & F: ATGACACCAAAACCСТCATCAA & \multirow{2}{*}{ NM_000230.2 } \\
\hline & R: GAAGTCCAAACCGGTGACTTT & \\
\hline \multirow{2}{*}{ PPARG2 } & F: CCTATTGACCCAGAAAGCGATT & \multirow{2}{*}{ NM_015869.4 } \\
\hline & R: CATTACGGAGAGATCCACGGA & \\
\hline
\end{tabular}

marker genes (FABP4/ $\alpha P 2, C E B P A / C / E B P-\alpha$, LEP/Leptin, and $P P A R G 2 / P P A R-\gamma 2$ ), and GAPDH (an internal standard) were evaluated using the primer sequences listed in Table 1. Real-time PCR was performed on a CFX96 Real-Time PCR System (Bio-Rad) following the manufacturer's protocol. Relative transcript levels were calculated as $\chi=2^{-\Delta \Delta \mathrm{Ct}}$, in which $\Delta \Delta \mathrm{Ct}=\Delta E-\Delta C, \Delta E=\mathrm{Ct}_{\exp }-\mathrm{Ct}_{\mathrm{GAPDH}}$, and $\Delta C=$ $\mathrm{Ct}_{\mathrm{ct} 1}-\mathrm{Ct}_{\mathrm{GAPDH}}$.

2.7. Statistical Analysis. Data from each experiment were expressed as the mean \pm standard error (S.E.). Statistic differences between groups were determined by one-way analysis of variance (ANOVA) followed by Student's unpaired $t$-test using the SPSS version 13.0 (SPSS Inc, Chicago, IL, USA). Significance was indicated by a $P$ value of $<0.05$ or $<0.01$ from Student's unpaired $t$-test.

\section{Results}

3.1. The Effect of Acoustic Vibration on Cell Proliferation of BM-MSCs. BM-MSCs were cultured in growth medium for 7 continuous days and stimulated with AFVS at $0,30,400$, and $800 \mathrm{~Hz}$. FDA staining showed the cell viability and BM-MSCs treated by AFVS at different frequencies maintained spindle and fibroblast-like cell shape (Figure 1(a)). At the time point of 3, 5, and 7 days, cell proliferation was assessed by CCK-8. On day 5, cell growth was higher by $13.6 \%$ in the $400 \mathrm{~Hz}$ group and by $10.5 \%$ in the $800 \mathrm{~Hz}$ group compared with the static group. On day 7, AFVS at $800 \mathrm{~Hz}$ induced the highest level of cell proliferation, $9.0 \%$ more than the $0 \mathrm{~Hz}$ group, $9.1 \%$ more than the $30 \mathrm{~Hz}$ group, and $22.8 \%$ more than the $400 \mathrm{~Hz}$ group (Figure 1(b)).
3.2. AFVS at $800 \mathrm{~Hz}$ Promotes Osteogenic Differentiation in BM-MSCs on Day 14. BM-MSCs were induced toward osteogenesis with the treatment of AFVS at $0,30,400$, and $800 \mathrm{~Hz}$. Cells in static culture condition $(0 \mathrm{~Hz})$ served as a positive control. Mineralization of the ECM, as a typical marker for osteogenic differentiation, was measured by Alizarin Red S staining on day 7 and day 14. AFVS at $800 \mathrm{~Hz}$ on day 14 stimulated a denser staining compared to the other three groups (Figure 2(a)). On day 7, AFVS at $30 \mathrm{~Hz}$ and $400 \mathrm{~Hz}$ increased the level of mineralization by $42.7 \%$ and $77.8 \%$, respectively, compared with the static group, whereas significant difference was not detected between the $0 \mathrm{~Hz}$ and $800 \mathrm{~Hz}$ groups (Figure 2(b)). However, on day 14, AFVS at $800 \mathrm{~Hz}$ stimulated the highest level of mineralization (by $21.3 \%$ compared with the static group). Mineralized areas in cells treated with AFVS at $30 \mathrm{~Hz}$ and $400 \mathrm{~Hz}$ declined by $11.7 \%$ and $25.8 \%$, respectively, compared with the static group (Figure 2(c)).

To evaluate the extent to which AFVS affected osteogenic differentiation, transcript levels of osteoblast-specific genes were examined. On day 7 , AFVS at $30 \mathrm{~Hz}$ and $400 \mathrm{~Hz}$ increased expression of COL1A1 by $29.1 \%$ and $70.6 \%$, respectively, compared with the static group (Figure 3(a)). Expression of ALP was elevated 1.56-fold higher by AFVS at $400 \mathrm{~Hz}$ relative to the corresponding untreated cells (Figure 3(b)). The transcription factor RUNX2 plays a critical role in MSC osteogenic differentiation, and AFVS at $30 \mathrm{~Hz}, 400 \mathrm{~Hz}$, and $800 \mathrm{~Hz}$ significantly upregulated the level by $57.6 \%, 32.3 \%$, and $30.0 \%$, respectively, in contrast to the static group (Figure 3(c)). Similarly, AFVS at $30 \mathrm{~Hz}$ and $400 \mathrm{~Hz}$ increased the mRNA level of SPP1 (Figure 3(d)). 

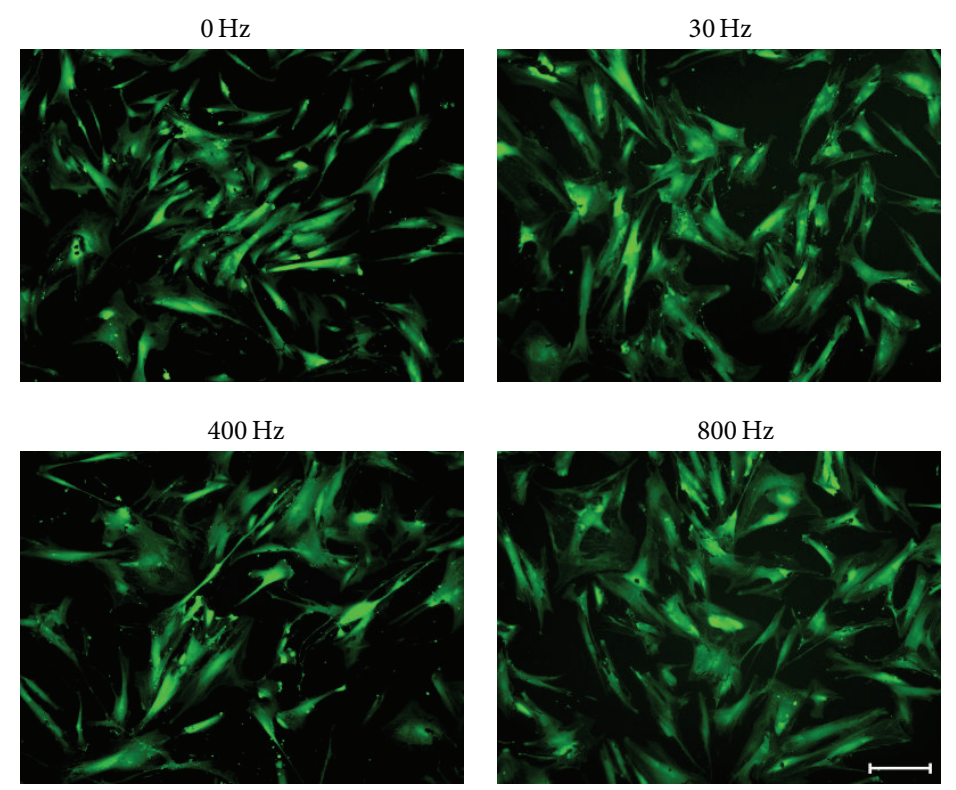

(a)

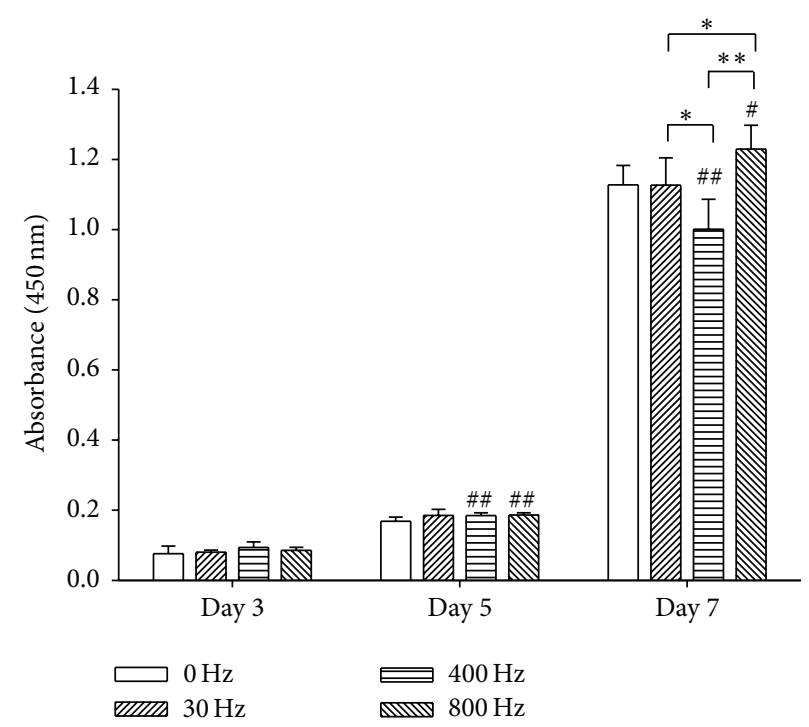

(b)

FIGURE 1: Effects of acoustic-frequency vibratory stimulation (AFVS) on cell viability and proliferation of human bone marrow-derived mesenchymal stem cells (BM-MSCs). (a) Fluorescein diacetate stain showed that BM-MSCs maintained spindle and fibroblast-like cell shape when stimulated with AFVS at the frequencies of 0,30, 400, and $800 \mathrm{~Hz}$. Scale bar $=200 \mu \mathrm{m}$. (b) Cell proliferation of BM-MSCs was improved by AFVS at $800 \mathrm{~Hz}$ on day 7. Values are mean \pm standard error of six independent experiments $(n=6) .{ }^{*} P<0.05$, ${ }^{* *} P<0.01$ in the indicated groups from unpaired $t$-test. ${ }^{\#} P<0.05,{ }^{\# \#} \mathrm{P}<0.01$ compared with the $0 \mathrm{~Hz}$ control group at the same time point from unpaired $t$-test.

On day 14 , AFVS at $800 \mathrm{~Hz}$ significantly increased expression of COL1A1 by $32.2 \%$ compared with the static group whereas AFVS at $30 \mathrm{~Hz}$ and $400 \mathrm{~Hz}$ downregulated the expression by $32.2 \%$ and $39.6 \%$, respectively (Figure $3(\mathrm{e})$ ). Regarding expression of ALP, RUNX2, and SPP1, AFVS at $800 \mathrm{~Hz}$ elevated the level of transcription by $58.1 \%, 5.1 \%$ ( $P=$ 0.582 ), and $63.7 \%$, respectively, relative to corresponding expression of $0 \mathrm{~Hz}$ cells. However, AFVS at $30 \mathrm{~Hz}$ and $400 \mathrm{~Hz}$ showed inhibitory effects on the expression of these three genes (Figures 3(f), 3(g), and 3(h)).
3.3. AFVS at $800 \mathrm{~Hz}$ Suppresses Adipogenic Differentiation in BM-MSCs on Day 21. Next, we investigated the effect of AFVS at different frequencies on adipogenesis of BM-MSCs. At the day 14 and day 21 time points, lipid accumulation was qualitatively and quantitatively determined by the Oil Red O stain. On day 21, adipocyte-like cells treated by AFVS at $800 \mathrm{~Hz}$ showed a smaller and lighter stain area compared with the 0,30 , and $400 \mathrm{~Hz}$ groups (Figure 4(a)). On both day 14 and day 21, AFVS at $800 \mathrm{~Hz}$ induced less lipid accumulation in differentiated BM-MSCs in contrast to the static group. 

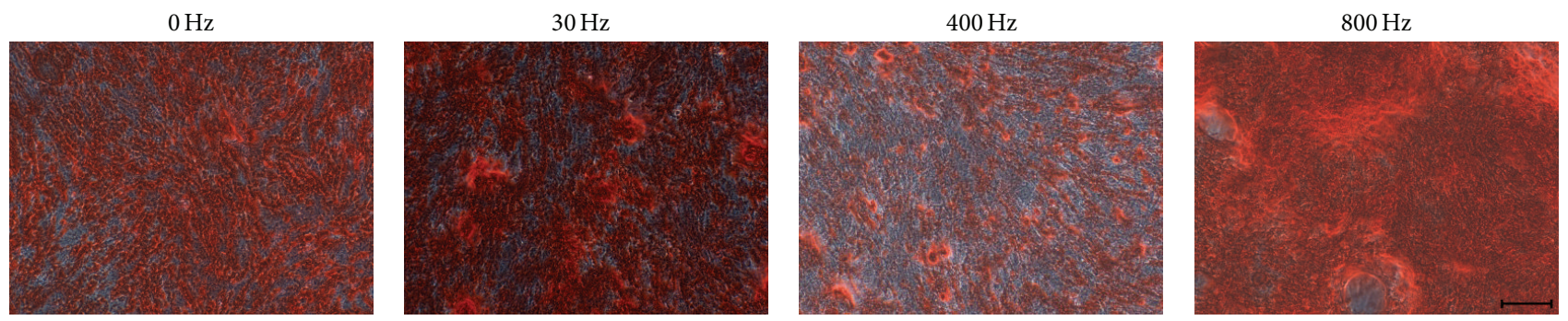

(a)

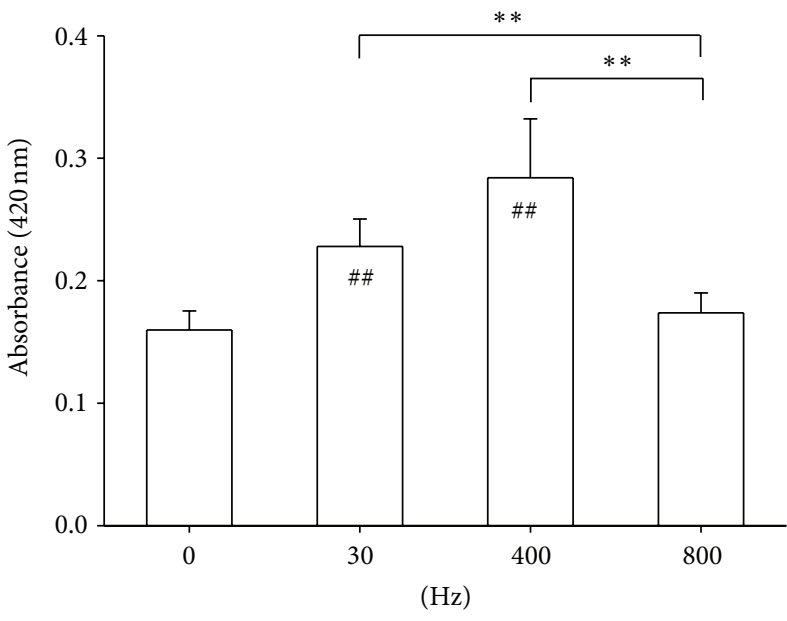

(b)

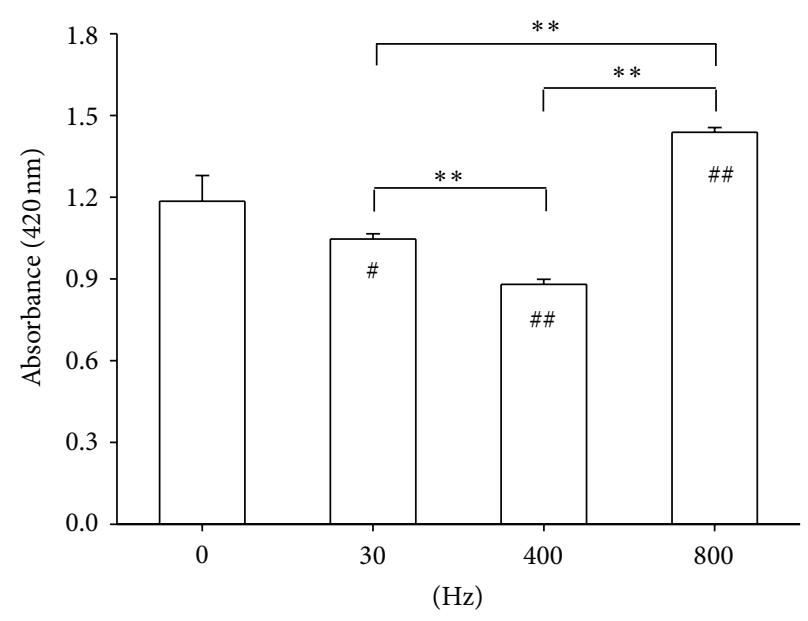

(c)

FIGURE 2: Effects of acoustic-frequency vibratory stimulation (AFVS) on mineralization of the extracellular matrix. Human bone marrowderived mesenchymal stem cells (BM-MSCs) were cultured in osteogenic differentiation medium for 14 days and stimulated with AFVS at the frequencies of $30 \mathrm{~Hz}, 400 \mathrm{~Hz}$, and $800 \mathrm{~Hz}$. Cells in static culture condition $(0 \mathrm{~Hz})$ served as a control. (a) At the time point of day 14, calcium deposition was assessed by Alizarin Red S staining. Scale bar $=200 \mu \mathrm{m}$. The stained mineral layers at the time point of day 7 (b) and 14 (c), respectively, were dissolved in $1 \%$ hydrochloric acid and quantified via a spectrophotometer. Values are mean \pm standard error of four independent experiments $(n=4) .{ }^{*} P<0.05,{ }^{* *} P<0.01$ in the indicated groups from unpaired $t$-test. ${ }^{\#} P<0.05$, ${ }^{\# \#} P<0.01$ compared with the $0 \mathrm{~Hz}$ control group from unpaired $t$-test.

However, AFVS at $400 \mathrm{~Hz}$ and AFVS at $30 \mathrm{~Hz}$ on day 21 increased lipid accumulation by $7.0 \%$ and $10.5 \%$, respectively, relative to corresponding populations of static cells (Figures 4(b) and 4(c)).

Expression of adipocyte-specific marker genes, such as $F A B P 4, C E B P A, P P A R G 2$, and $L E P$, was determined by realtime RT-PCR. On day 14, AFVS at 30 and $400 \mathrm{~Hz}$ promoted levels of FABP4 by 1.3 -fold and 1.0-fold, respectively, compared with the static control group, whereas AFVS at $800 \mathrm{~Hz}$ decreased the expression by $41.3 \%$ (Figure 5(a)). Similarly, AFVS at 30 and $400 \mathrm{~Hz}$ upregulated levels of CEBPA, PPARG2, and $L E P$ while AFVS at $800 \mathrm{~Hz}$ suppressed expression (Figures 5(b), 5(c), and 5(d)). On day 21, the AFVS $30 \mathrm{~Hz}$ group generated the highest level of adipogenic markers by 4.0 -fold for FABP4, 4.2-fold for CEBPA, 4.6-fold for $P P A R G 2$, and 1.5-fold for $L E P$, in contrast to the static group (Figures 5(e), 5(f), 5(g), and 5(h)). In agreement with Oil Red O stain results, AFVS at $800 \mathrm{~Hz}$ significantly downregulated levels of adipogenic genes by $81.6 \%$ for FABP4, $74.0 \%$ for CEBPA, $49.1 \%$ for PPARG2, and $54.1 \%$ for LEP, relative to corresponding populations of the control cells (Figures 5(e), 5(f), 5(g), and 5(h)).

\section{Discussion}

To our knowledge, this is the first study to report that mechanical vibration at acoustic frequencies can modulate lineage-specific differentiation in BM-MSCs. More specifically, osteogenesis is promoted but adipogenesis is inhibited by AFVS at the frequency of $800 \mathrm{~Hz}$. Mechanical force vibration has been shown to promote bone formation and treat bone loss arising from disability or osteoporotic conditions under a vibration $(<100 \mathrm{~Hz})$ to the human whole body in preclinical and clinical trials [19]. However, the whole body vibration experienced significant energy absorption from the soft tissues, leading to a declination of the vibration efficiency in bone. Furthermore, most internal organs have their low frequency of resonance, so inappropriate whole body vibration may cause much more serious damage to the patients [20]. In contrast, the higher frequency is more suitable for local vibration. Sonic waves can be emitted locally to the area where the treatments are required, for example, the proximal femur or spine. While acoustic frequencies cover a wide range of $20-20,000 \mathrm{~Hz}$, we found that three frequencies at 30,400 , and $800 \mathrm{~Hz}$ resulted in the same 


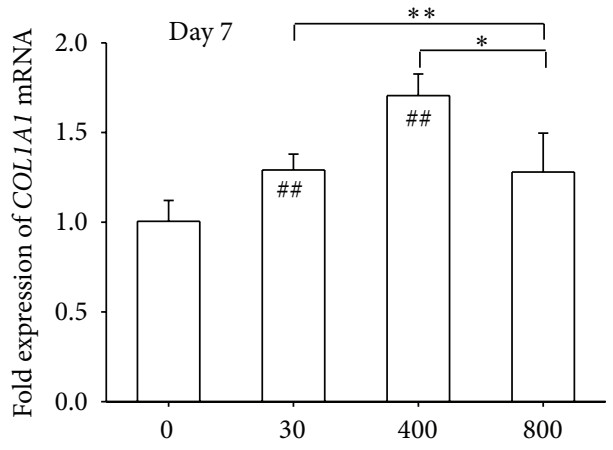

(a)

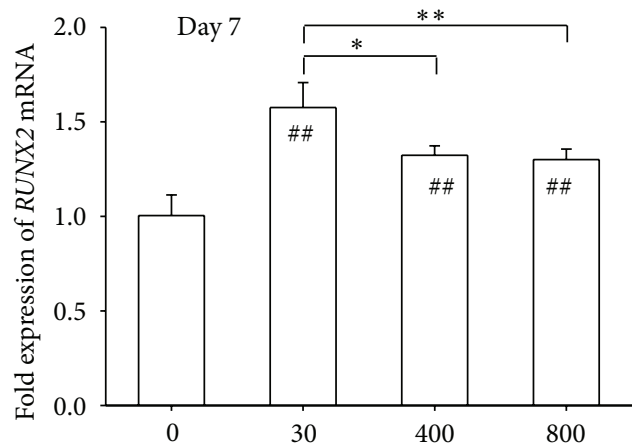

(c)

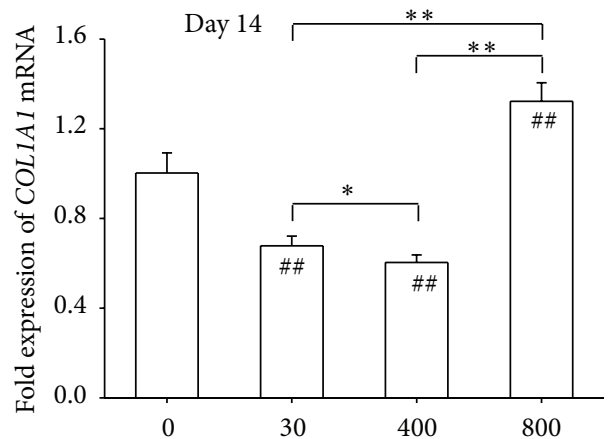

(e)

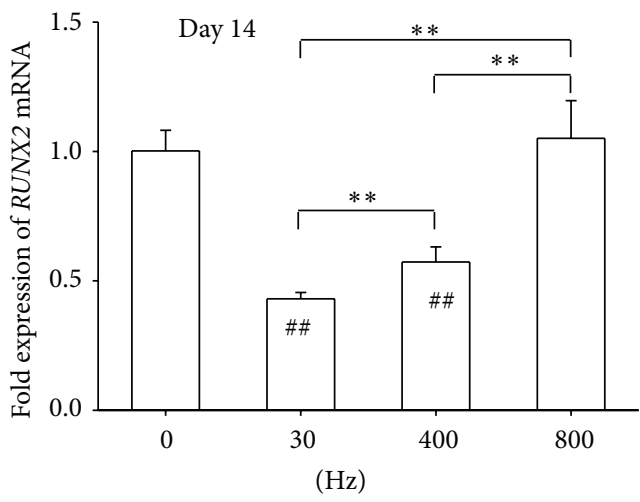

(g)

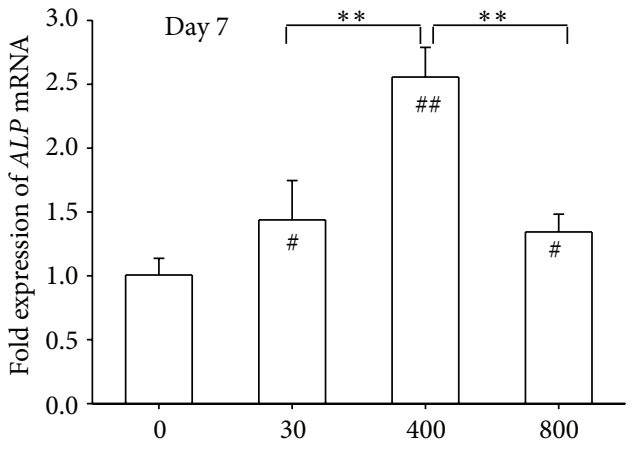

(b)

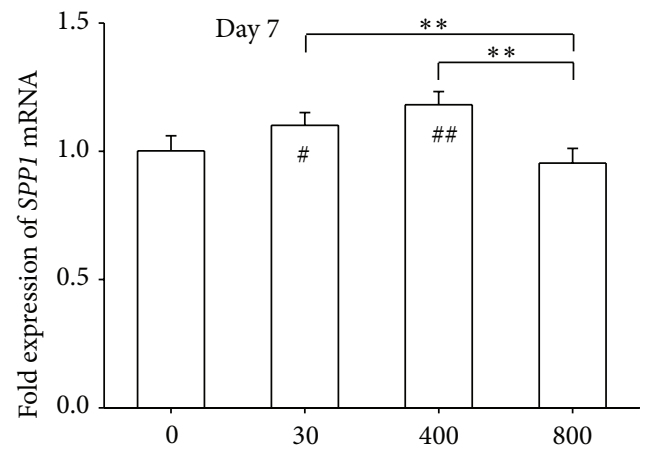

(d)

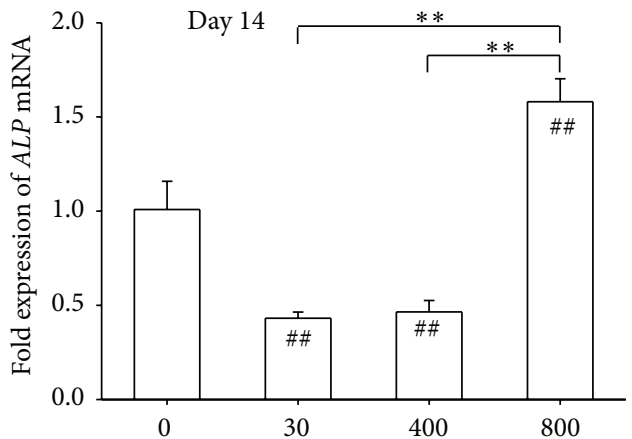

(f)

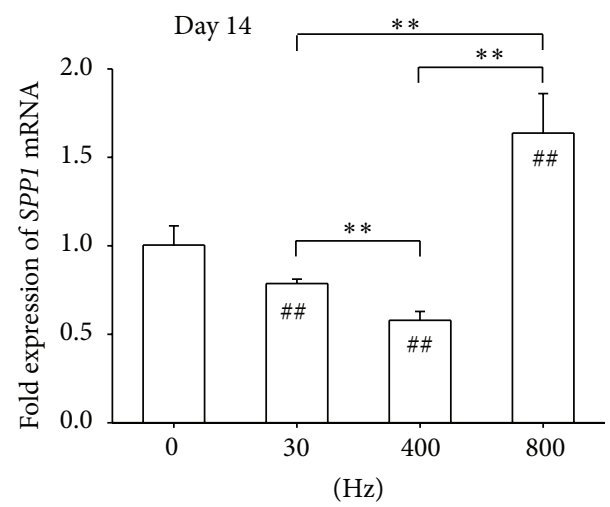

(h)

FIGURE 3: Acoustic-frequency vibratory stimulation (AFVS) modulates expression of mRNA encoding osteogenesis-specific markers in human bone marrow-derived mesenchymal stem cells (BM-MSCs) at the time points of day 7 ((a), (b), (c), and (d)) and day 14 ((e), (f), $(\mathrm{g})$, and $(\mathrm{h}))$. The mRNA levels of COL1A1 ((a), (e)), ALP ((b), (f)), RUNX2 ((c), (g)), and SPP1 ((d), (h)) were measured by real-time RT-PCR. Values are mean \pm standard error of four independent experiments $(n=4)$. ${ }^{*} P<0.05,{ }^{* *} P<0.01$ in the indicated groups from unpaired $t$-test. ${ }^{\#} P<0.05,{ }^{\# \#} P<0.01$ compared with the $0 \mathrm{~Hz}$ control group from unpaired $t$-test. 

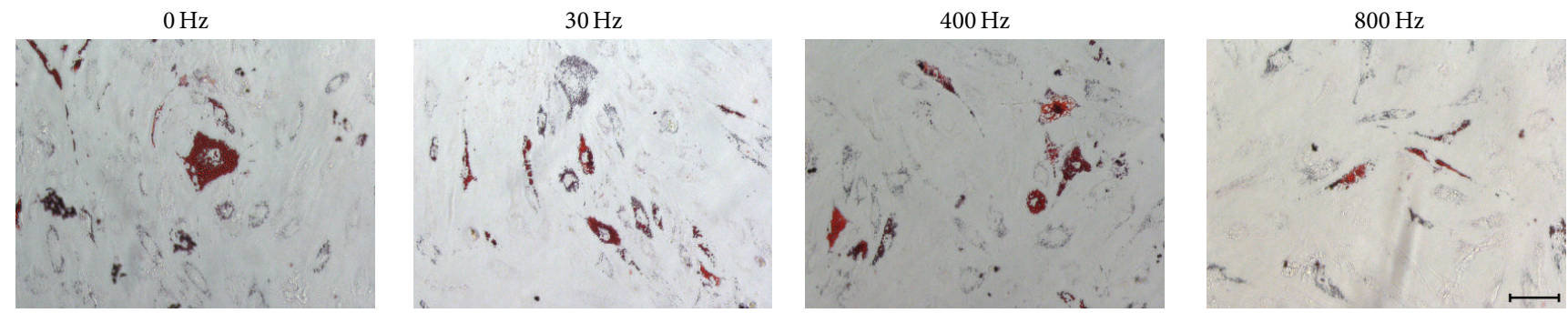

(a)

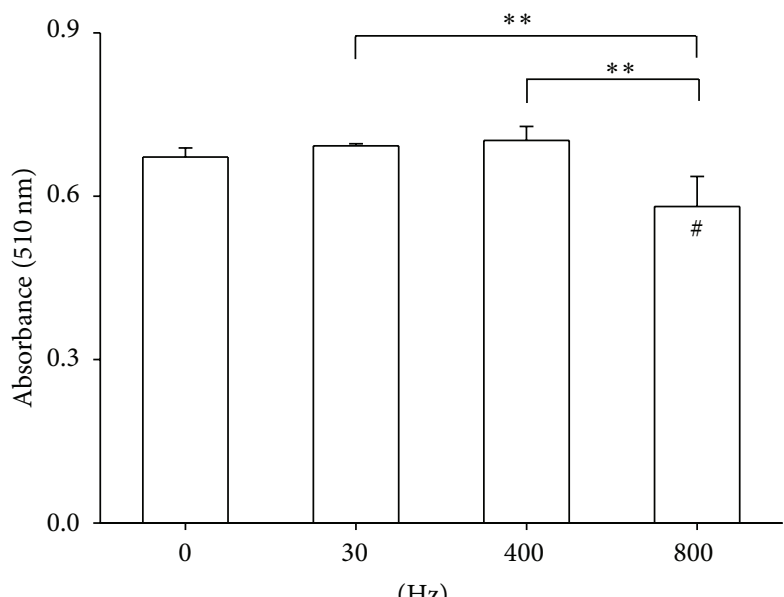

(b)

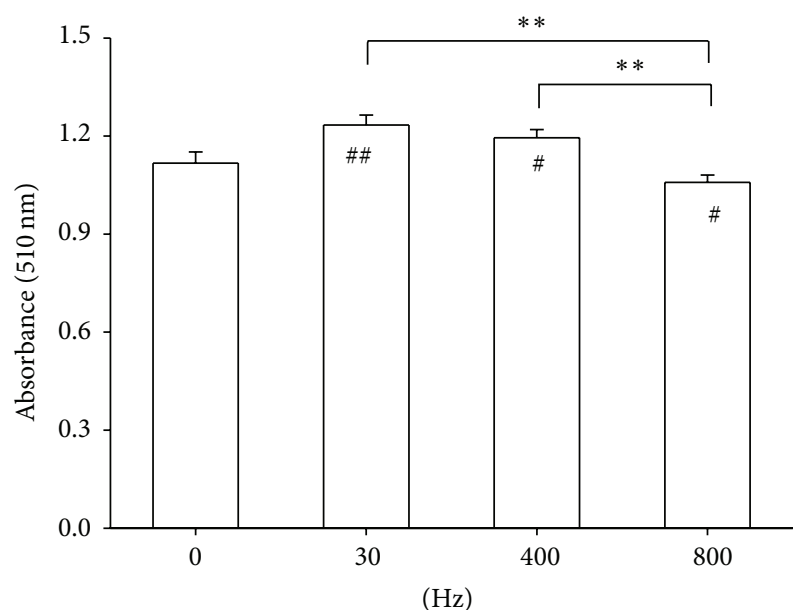

(c)

FIGURE 4: Effects of acoustic-frequency vibratory stimulation (AFVS) on lipid accumulation in adipocyte-like cells. Human bone marrowderived mesenchymal stem cells (BM-MSCs) were incubated in adipogenic differentiation medium for 21 days and stimulated with AFVS at the frequencies of $30 \mathrm{~Hz}, 400 \mathrm{~Hz}$, and $800 \mathrm{~Hz}$. Cells in static culture condition $(0 \mathrm{~Hz})$ served as a control. (a) At the time point of day 21, lipid accumulation was assessed by Oil Red O staining. Scale bar $=200 \mu \mathrm{m}$. The lipid-bound stain at the time point of day 14 (b) and 21 (c), respectively, was dissolved in isopropanol and quantified via a spectrophotometer. Values are mean \pm standard error of four independent experiments $(n=4) .{ }^{*} P<0.05,{ }^{* *} P<0.01$ in the indicated groups from unpaired $t$-test. ${ }^{\#} P<0.05,{ }^{\# \#} P<0.01$ compared with the $0 \mathrm{~Hz}$ control group from unpaired $t$-test.

vibration amplitude of the cell culture plates. Therefore, we selectively used AFVS at these three frequencies as the first step to explore how BM-MSCs respond to vibration loading in this study. We found that AFVS did not damage cell viability but also vibration at $800 \mathrm{~Hz}$ showed an improved effect on cell proliferation.

BM-MSCs hold the capacity to differentiate into multiple cell types and thus they are considered ideal therapeutic cell sources for regenerative medicine and tissue engineering. We chose to use BM-MSCs because, as the progenitor cells of osteoblasts and adipocytes, the balance between osteogenic and adipogenic differentiation is closely related to the stability of bone remodeling. Once BM-MSCs are driven to differentiate toward one cell type, another cell fate is simultaneously inhibited [21]. In the case of osteoporosis, BMMSCs gradually lose the ability of osteogenic differentiation but its ability of adipogenic differentiation increases. The distribution of balance has been considered as one of the reasons of osteoporotic generation [22].

The period of osteogenic differentiation was planned for a continuous 21 days [23] in accordance with adipogenesis; however, we found that osteoblast-like cells dissociated from cell plates after 2 weeks, so BM-MSCs were induced toward osteoblasts for only 14 days [18]. The cause of this phenomenon was possibly due to ECM accumulation and vibratory stimulation. As osteogenesis proceeded, coincidentally, the adhesive strength between the ECM and cell culture surface became weaker. Meanwhile, mechanical stimulation may accelerate the detachment of differentiated cells and ECM from culture plates. Thus, we will modify tissue culture polystyrene plates to increase the adhesive force [24] and analyze the long-term effect of AFVS on MSC osteogenesis.

The staining for mineralized ECM was barely visible at the time point of day 7 (data not shown), but the quantification of dye-bound mineral layers showed that AFVS at the frequencies of 30 and $400 \mathrm{~Hz}$ promoted matrix mineralization. Several previous studies demonstrated that low-magnitude vibrations at the frequency of $30 \mathrm{~Hz}$ facilitate the osteogenic process in preosteoblast cell lines [25] and MSCs [26]. Dumas et al. demonstrated that mechanical vibration at the frequency of $400 \mathrm{~Hz}$ enhanced osteogenic differentiation of C3H10T1/2 MSCs both at mRNA and protein levels [27], which is consistent with our results. Nevertheless, our study indicated that $30 \mathrm{~Hz}$ could indeed promote osteogenesis of 


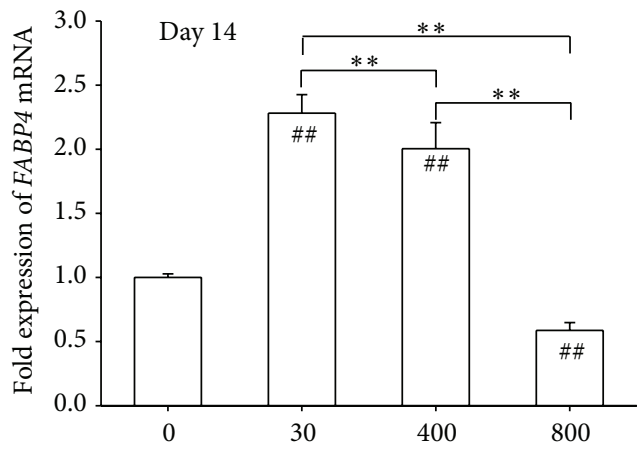

(a)

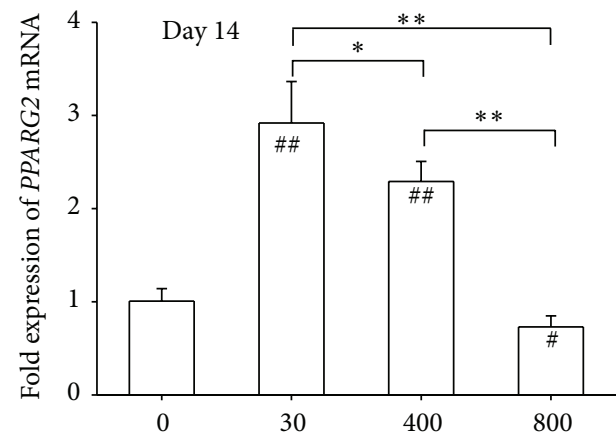

(c)

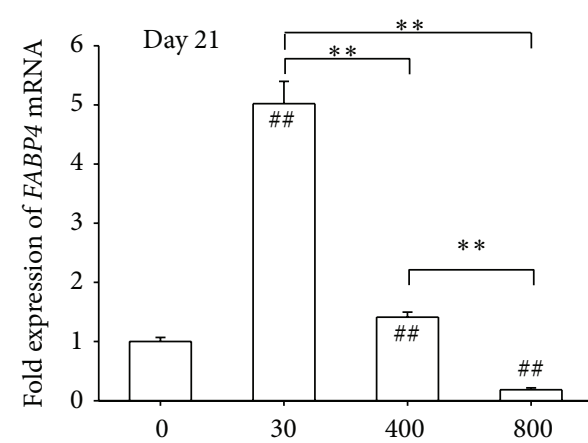

(e)

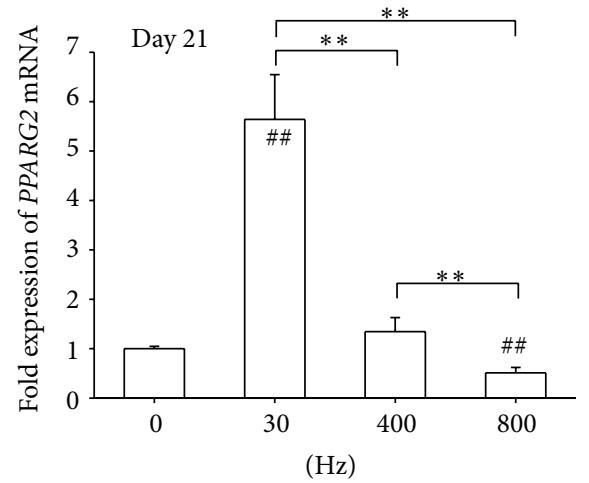

(g)

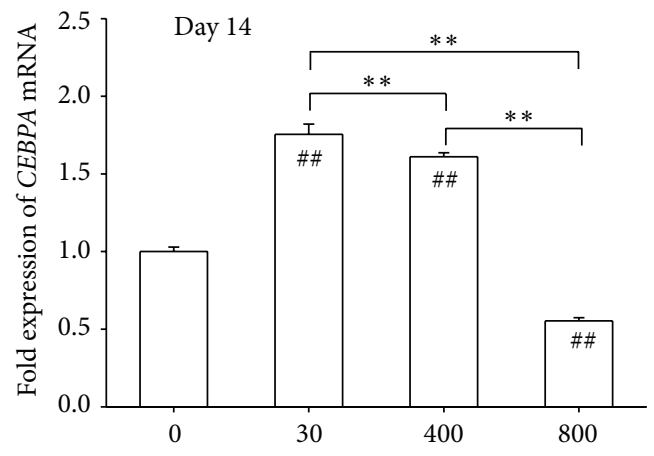

(b)

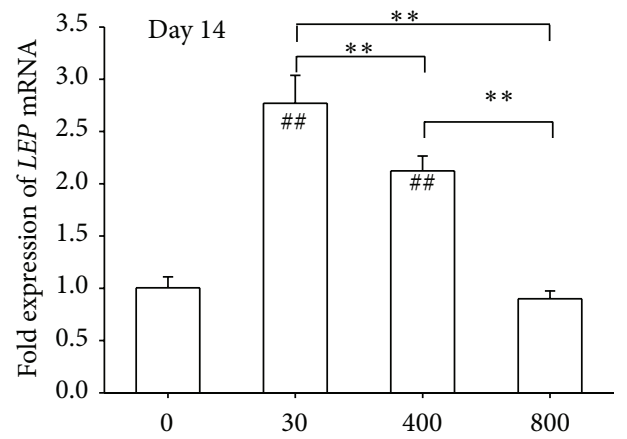

(d)

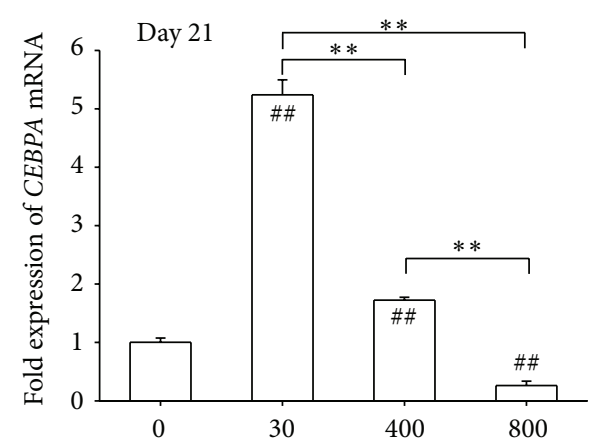

(f)

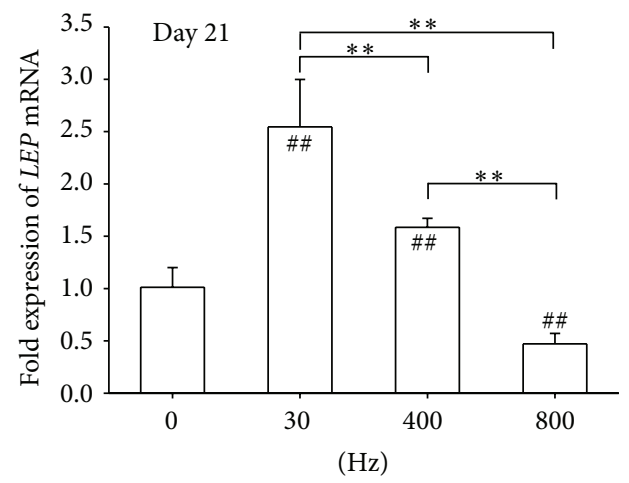

(h)

FIGURE 5: Acoustic-frequency vibratory stimulation (AFVS) modulates expression of mRNA encoding adipogenesis-specific markers in human bone marrow-derived mesenchymal stem cells (BM-MSCs) at the time points of day 14 ((a), (b), (c), and (d)) and day 21 ((e), (f), (g), and (h)), respectively. The mRNA levels of FABP4 ((a), (e)), CEBPA ((b), (f)), PPARG2 ((c), (g)), and LEP ((d), (h)) were measured by real-time RT-PCR. Values are mean \pm standard error of four independent experiments $(n=4) .{ }^{*} P<0.05,{ }^{* *} P<0.01$ in the indicated groups from unpaired $t$-test. ${ }^{\#} P<0.05,{ }^{\# \#} P<0.01$ compared with the $0 \mathrm{~Hz}$ control group from unpaired $t$-test. 
BM-MSCs at early stage but suppress osteogenesis at late stage. Interestingly, our data also showed that $800 \mathrm{~Hz}$ had no apparent effect on osteogenesis on day 7 but improved osteoblast maturation on day 14. The osteogenic process of MSCs is usually divided into three distinct stages: osteoblastlike cell formation, matrix production, and matrix mineralization [28]. Thus, we speculate that mechanosensitive receptors on BM-MSC cell surfaces undergo a drastic change during osteogenic differentiation and therefore respond to different frequencies at the different stages. Future studies will be conducted to determine what changes in the mechanosensitive receptors occur during osteogenesis as well as the underlying mechanism for sensing mechanical stimuli.

Osteogenic and adipogenic differentiation of BM-MSCs are opposite processes, and our results revealed that $30 \mathrm{~Hz}$ stimulation favored cell adipogenic differentiation, in agreement with previous studies [29]. More importantly, we found that $800 \mathrm{~Hz}$ mechanical vibration suppressed the commitment of BM-MSCs to adipogenic lineage, as demonstrated by decreased transcripts of PPARG/PPAR- $\gamma 2$, which is a master regulator of adipogenesis and osteogenesis. It has been demonstrated that PPAR- $\gamma 2$ binds to the $\mathrm{C} / \mathrm{EBP} \alpha$ promoter to activate its expression and accelerates the process of adipogenesis [30], while silencing PPAR- $\gamma 2$ through small interfering RNAs leads to retardation of adipogenesis but improvement of osteogenesis [31]. Meanwhile, the $800 \mathrm{~Hz}$ vibration induced commitment of BM-MSCs to osteogenic lineage accompanied by increased RUNX2 expression, which acted as an essential activator to induce osteogenic differentiation. The ERK1/2 signaling pathway may be involved in AFVS-induced BM-MSC osteogenesis. Zhou et al. showed that high-frequency vibration induced sustained phosphorylation of ERK1/2 during the process of osteogenesis and blockage of ERK1/2 transduction resulted in decreased alkaline phosphatase activity [32]. Another potential mechanism of mechanotransduction may relate to Wnt activation, especially Wnt10b, which was simultaneously up-regulated in MC3T3-E1 preosteoblast cells with exposure to vibrations [33]. However, the cellular signaling pathways regulating vibration-induced cell differentiation remain unclear and further investigation may elucidate underlying molecular mechanisms that determine cell fate by biasing the lineage commitment of BM-MSCs.

\section{Conclusions}

Our study provided a first glimpse at the influence of AFVS on commitment of BM-MSCs to osteogenesis and adipogenesis. BM-MSCs showed a frequency-dependent response to mechanical vibration. Acoustic vibration at $800 \mathrm{~Hz}$ but not $30 \mathrm{~Hz}$ nor $400 \mathrm{~Hz}$ was the most favorable for osteogenic differentiation and simultaneously inhibited adipogenesis. Further studies are necessary to verify the long-term viability and commitment to lineage-specific differentiation of BMMSCs, with the purpose of determining whether acoustic vibration could potentially become a novel means to treat osteoporosis.

\section{Conflict of Interests}

The authors declare that there is no conflict of interests regarding the publication of this paper.

\section{Authors' Contribution}

Xi Chen and Fan He contributed equally to this work.

\section{Acknowledgments}

The authors are grateful to Michelle Si and Joseph Jargstorf for carefully reviewing and editing the paper. This work was supported by the National Natural Science Foundation of China (no. 31270995, no. 81320108018, and no. 51203194); Natural Science Foundation of Jiangsu Province (no. BK20140323); Jiangsu Provincial Special Program of Medical Science (BL2012004); the Priority Academic Program Development of Jiangsu Higher Education Institutions; Scientific Research Foundation for the Returned Overseas Chinese Scholars, State Education Ministry.

\section{References}

[1] C. Cooper, Z. A. Cole, C. R. Holroyd et al., "Secular trends in the incidence of hip and other osteoporotic fractures," Osteoporosis International, vol. 22, no. 5, pp. 1277-1288, 2011.

[2] S. Maria and P. A. Witt-Enderby, "Melatonin effects on bone: potential use for the prevention and treatment for osteopenia, osteoporosis, and periodontal disease and for use in bonegrafting procedures," Journal of Pineal Research, vol. 56, no. 2, pp. 115-125, 2014.

[3] Y. Mikami, T. Matsumoto, K. Kano et al., "Current status of drug therapies for osteoporosis and the search for stem cells adapted for bone regenerative medicine," Anatomical Science International, vol. 89, no. 1, pp. 1-10, 2014.

[4] L. Si, T. M. Winzenberg, and A. J. Palmer, "A systematic review of models used in cost-effectiveness analyses of preventing osteoporotic fractures," Osteoporosis International, vol. 25, no. 1, pp. 51-60, 2014.

[5] E. J. Moerman, K. Teng, D. A. Lipschitz, and B. LeckaCzernik, "Aging activates adipogenic and suppresses osteogenic programs in mesenchymal marrow stroma/stem cells: the role of PPAR-gamma2 transcription factor and TGF-beta/BMP signaling pathways," Aging Cell, vol. 3, no. 6, pp. 379-389, 2004.

[6] M. F. Pittenger, A. M. Mackay, S. C. Beck et al., "Multilineage potential of adult human mesenchymal stem cells," Science, vol. 284, no. 5411, pp. 143-147, 1999.

[7] M. E. Nuttall and J. M. Gimble, "Is there a therapeutic opportunity to either prevent or treat osteopenic disorders by inhibiting marrow adipogenesis?” Bone, vol. 27, no. 2, pp. 177-184, 2000.

[8] M. Kawai and C. J. Rosen, "PPARgamma: a circadian transcription factor in adipogenesis and osteogenesis," Nature Reviews Endocrinology, vol. 6, no. 11, pp. 629-636, 2010.

[9] S. M. P. Verschueren, M. Roelants, C. Delecluse, S. Swinnen, D. Vanderschueren, and S. Boonen, "Effect of 6-month whole body vibration training on hip density, muscle strength, and postural control in postmenopausal women: a randomized controlled pilot study," Journal of Bone and Mineral Research, vol. 19, no. 3, pp. 352-359, 2004. 
[10] H. Nikukar, S. Reid, P. M. Tsimbouri, M. O. Riehle, A. S. G. Curtis, and M. J. Dalby, "Osteogenesis of mesenchymal stem cells by nanoscale mechanotransduction," ACS Nano, vol. 7, no. 3, pp. 2758-2767, 2013.

[11] B. Sen, Z.-H. Xie, N. Case, M. Styner, C. T. Rubin, and J. Rubin, "Mechanical signal influence on mesenchymal stem cell fate is enhanced by incorporation of refractory periods into the loading regimen," Journal of Biomechanics, vol. 44, no. 4, pp. 593-599, 2011.

[12] D. Prè, G. Ceccarelli, G. Gastaldi et al., "The differentiation of human adipose-derived stem cells (hASCs) into osteoblasts is promoted by low amplitude, high frequency vibration treatment," Bone, vol. 49, no. 2, pp. 295-303, 2011.

[13] Y. K. Luu, E. Capilla, C. J. Rosen et al., "Mechanical stimulation of mesenchymal stem cell proliferation and differentiation promotes osteogenesis while preventing dietary-induced obesity," Journal of Bone and Mineral Research, vol. 24, no. 1, pp. 50-61, 2009.

[14] G. Uzer, S. Pongkitwitoon, M. Ete Chan, and S. Judex, "Vibration induced osteogenic commitment of mesenchymal stem cells is enhanced by cytoskeletal remodeling but not fluid shear," Journal of Biomechanics, vol. 46, no. 13, pp. 2296-2302, 2013.

[15] K. H. Wenger, J. D. Freeman, S. Fulzele et al., "Effect of wholebody vibration on bone properties in aging mice," Bone, vol. 47, no. 4, pp. 746-755, 2010.

[16] X. Liu, Y. Xu, S. Chen et al., "Rescue of proinflammatory cytokine-inhibited chondrogenesis by the antiarthritic effect of melatonin in synovium mesenchymal stem cells via suppression of reactive oxygen species and matrix metalloproteinases," Free Radical Biology and Medicine, vol. 68, pp. 234-246, 2014.

[17] F. He, X. Chen, and M. Pei, "Reconstruction of an in vitro tissuespecific microenvironment to rejuvenate synovium-derived stem cells for cartilage tissue engineering," Tissue Engineering A, vol. 15, no. 12, pp. 3809-3821, 2009.

[18] F. He, X. Liu, K. Xiong et al., "Extracellular matrix modulates the biological effects of melatonin in mesenchymal stem cells," Journal of Endocrinology, vol. 223, no. 2, pp. 167-180, 2014.

[19] C. T. Rubin, R. Recker, D. Cullen, J. Ryaby, J. McCabe, and K. McLeod, "Prevention of postmenopausal bone loss by a lowmagnitude, high-frequency mechanical stimuli: a clinical trial assessing compliance, efficacy, and safety," Journal of Bone and Mineral Research, vol. 19, no. 3, pp. 343-351, 2004.

[20] J. Mester, H. Kleinöder, and Z. Yue, "Vibration training: benefits and risks," Journal of Biomechanics, vol. 39, no. 6, pp. 1056-1065, 2006.

[21] E. D. Rosen and O. A. MacDougald, "Adipocyte differentiation from the inside out," Nature Reviews Molecular Cell Biology, vol. 7, no. 12, pp. 885-896, 2006.

[22] Y. Tokuzawa, K. Yagi, Y. Yamashita et al., "Id4, a new candidate gene for senile osteoporosis, acts as a molecular switch promoting osteoblast differentiation," PLoS Genetics, vol. 6, no. 7, Article ID e1001019, 2010.

[23] X. Liu, Y. Gong, K. Xiong et al., "Melatonin mediates protective effects on inflammatory response induced by interleukin-1 beta in human mesenchymal stem cells," Journal of Pineal Research, vol. 55, no. 1, pp. 14-25, 2013.

[24] H. He, X. Liu, L. Peng et al., "Promotion of hepatic differentiation of bone marrow mesenchymal stem cells on decellularized cell-deposited extracellular matrix," BioMed Research International, vol. 2013, Article ID 406871, 11 pages, 2013.

[25] M. J. Patel, H. C. Kyungh, M. C. Sykes, R. Talish, C. Rubin, and $\mathrm{H}$. Jo, "Low magnitude and high frequency mechanical loading prevents decreased bone formation responses of 2T3 preosteoblasts," Journal of Cellular Biochemistry, vol. 106, no. 2, pp. 306-316, 2009.

[26] I. S. Kim, Y. M. Song, B. Lee, and S. J. Hwang, "Human mesenchymal stromal cells are mechanosensitive to vibration stimuli," Journal of Dental Research, vol. 91, no. 12, pp. 1135-1140, 2012.

[27] V. Dumas, B. Ducharne, A. Perrier et al., "Extracellular matrix produced by osteoblasts cultured under low-magnitude, highfrequency stimulation is favourable to osteogenic differentiation of mesenchymal stem cells," Calcified Tissue International, vol. 87, no. 4, pp. 351-364, 2010.

[28] G. R. Beck Jr., "Inorganic phosphate as a signaling molecule in osteoblast differentiation," Journal of Cellular Biochemistry, vol. 90, no. 2, pp. 234-243, 2003.

[29] E.-S. Oh, Y.-K. Seo, H.-H. Yoon, H. Cho, M.-Y. Yoon, and J.K. Park, "Effects of sub-sonic vibration on the proliferation and maturation of 3T3-L1 cells," Life Sciences, vol. 88, no. 3-4, pp. 169-177, 2011.

[30] Q.-H. Zhao, S.-G. Wang, S.-X. Liu et al., "PPAR $\gamma$ forms a bridge between DNA methylation and histone acetylation at the $\mathrm{C} / \mathrm{EBP} \alpha$ gene promoter to regulate the balance between osteogenesis and adipogenesis of bone marrow stromal cells," FEBS Journal, vol. 280, no. 22, pp. 5801-5814, 2013.

[31] M.-J. Lee, H.-T. Chen, M.-L. Ho et al., "PPARgamma silencing enhances osteogenic differentiation of human adipose-derived mesenchymal stem cells," Journal of Cellular and Molecular Medicine, vol. 17, no. 9, pp. 1188-1193, 2013.

[32] Y. Zhou, X. Guan, Z. Zhu et al., "Osteogenic differentiation of bone marrow-derived mesenchymal stromal cells on bonederived scaffolds: effect of microvibration and role of ERK1/2 activation," European Cells and Materials Journal, vol. 22, pp. 12-25, 2011.

[33] W. W. Hou, Z. L. Zhu, Y. Zhou, C. X. Zhang, and H. Y. $\mathrm{Yu}$, "Involvement of Wnt activation in the micromechanical vibration-enhanced osteogenic response of osteoblasts," Journal of Orthopaedic Science, vol. 16, no. 5, pp. 598-605, 2011. 


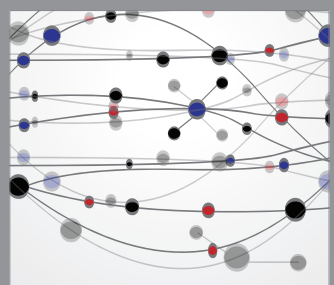

The Scientific World Journal
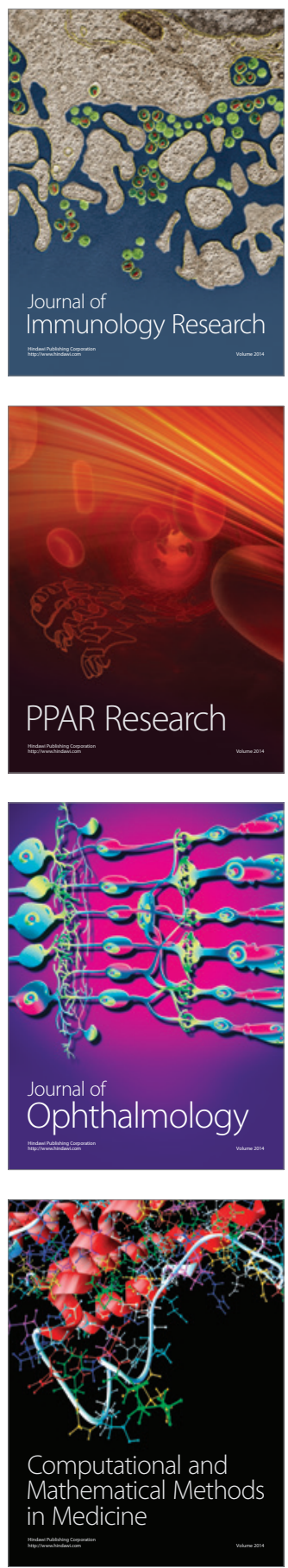

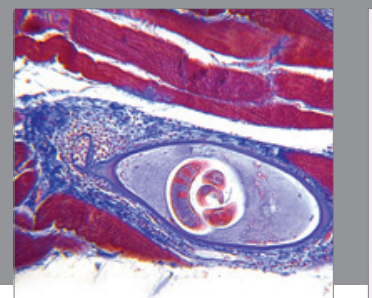

Gastroenterology

Research and Practice
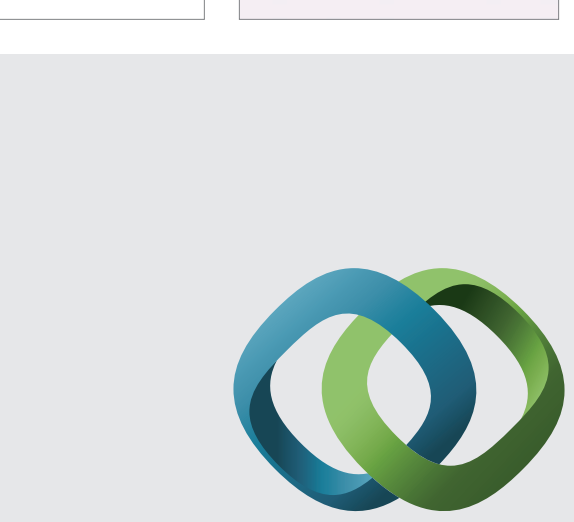

\section{Hindawi}

Submit your manuscripts at

http://www.hindawi.com
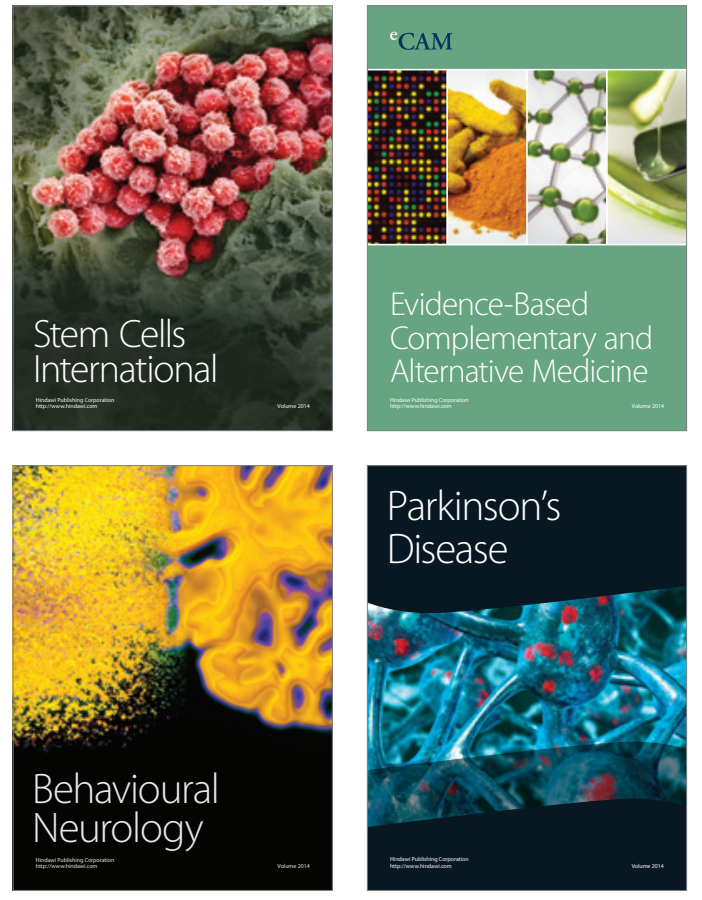
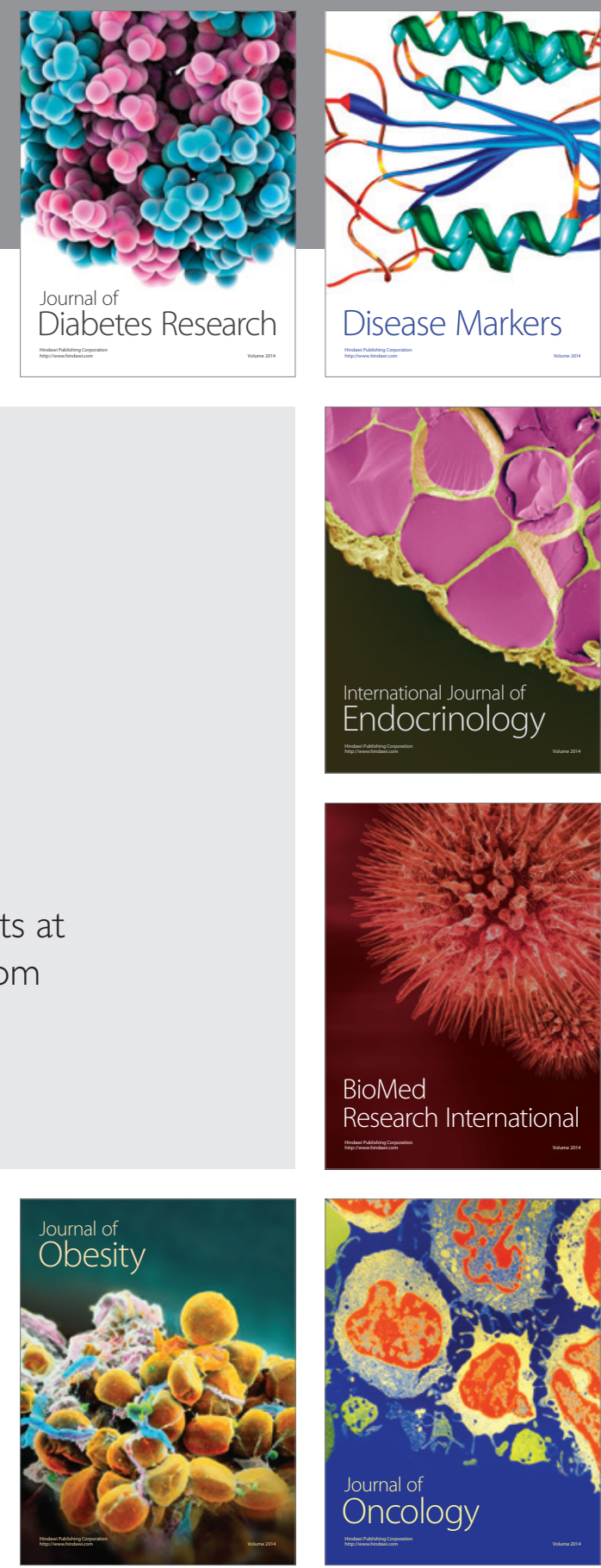

Disease Markers
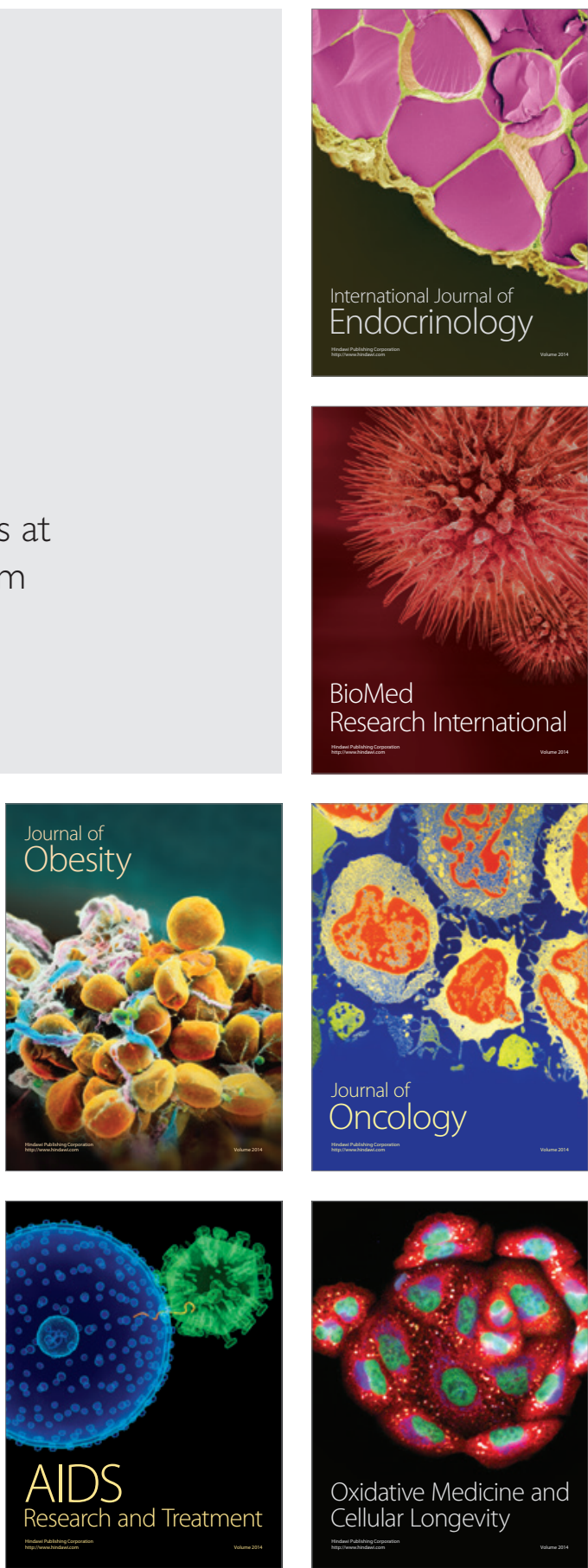